\title{
RESSIGNIFICANDO A RELAÇÃO ESCOLA-UNIVERSIDADE PELO TEMPO: DIFICULDADES, DESAFIOS E CONQUISTAS
}

\author{
Raquel Gomes de Oliveira \\ Universidade Estadual Paulista Júlio de Mesquita Filho (UNESP), \\ Presidente Prudente, São Paulo, Brasil
}

\begin{abstract}
Resumo: A Resolução n॰ 09/69 do Conselho Federal de Educação instituiu a obrigatoriedade da Prática de Ensino nas licenciaturas na forma de Estágio Supervisionado. Motivados pela comemoração dos 50 anos de sua publicação, apresentamos uma breve incursão histórica sobre a realização da Prática de Ensino e do Estágio Supervisionado de formação de professores, tendo como contexto a relação escola-universidade, e como desafios e conquistas dessa relação, que se apresentam ao longo do tempo, têm contribuído para sua ressignificação, em termos de uma parceria, ao considerar demandas relacionais e formativas, tanto as das escolas como as da formação de professores.
\end{abstract}

Palavras-chave: Parceria. Docência. Prática de Ensino. Estágio Supervisionado.

Introdução

A preocupação com a formação pedagógica do professor, à luz de sua futura atuação profissional na escola, atentando para a formação integral de seus alunos, é anterior à publicação da Resolução CFE 09/69.

[...] não se há de entender como professor [...] aquele que apenas cumpre mecanicamente a tarefa de 'dar aulas'. Todo professor é basicamente um educador; e só age como tal o que faz de cada ensino particularizado um instrumento para a formação integral do aluno. [...] o futuro aluno constitui o dado fundamental [...] na preparação pedagógica dos licenciados; e a partir dessa constante. (PARECER CFE n² 292/62, BRASIL, 1962).

Contudo, o tempo dessa formação pedagógica somente foi previsto no Parecer CFE 672/69, que propôs como anteprojeto a Resolução CFE 09/69, na qual a Prática de Ensino foi considerada como espaço formativo docente, "[...] em situação real e preferencialmente nas escolas" (DOCUMENTA, 1969, p. 117). A memoração conjunta (comemoração) dos seus 50 anos de publicação oportuniza assumirmos dificuldades, conquistas e superações relativas à relação escola-universidade, entendida como 
contexto de desenvolvimento da Prática de Ensino e do Estágio Supervisionado de futuros professores como referências para a ressignificação dessa relação.

Neste artigo, apresentamos como ressignificações e reelaborações para a relação escola-universidade podem ser consequências de concepções que fundamentam as licenciaturas, bem como de suas diretrizes e igualmente de resultados de pesquisas que descrevem a realização da Prática de Ensino e do Estágio Supervisionado em contextos escolares, que buscam denominar como parceria a relação escola-universidade ao considerarem demandas organizacionais, relacionais e formativas, tanto as escolares como as universitárias, para alcançarem benefícios mútuos.

\section{UMA BREVE INCURSÃO HISTÓRIA DA PRÁTICA DE ENSINO E DO ESTÁGIO SUPERVISIONADO}

Para Pimenta (2002), a Prática de Ensino e o Estágio Supervisionado são influenciados pelo entendimento histórico-social da profissão docente, tendo a dimensão prática inicialmente assumido o papel de elemento formador até aos entendimentos recentes, nos quais o Estágio Supervisionado é uma atividade de Prática de Ensino, que pode se referendar pela concepção de unidade entre teoria e prática.

Desde os anos 60, a relação escola-universidade contextualizou, dada à realização da Prática de Ensino e do Estágio Supervisionado, entendimentos para essas disciplinas, que variam entre a aquisição de experiência docente, a instrumentalização e treinamento de habilidades docentes e, por fim, a vivência da prática social reflexiva e intencional, no sentido de uma iniciação à práxis (PIMENTA, 2002).

Na relação escola-universidade predominava a dissociação entre teoria e prática, que ao salientar o distanciamento entre a formação nas licenciaturas e as demandas escolares, acabou levando à necessidade de rever o entendimento no qual na escola aplicavam-se saberes exclusivamente aprendidos na licenciatura. Nesse sentido, a busca pela unidade teoria e prática (PIMENTA, 2002), ao considerar a escola como lugar de prática, mas também de elaboração teórica, de construção de saberes, possibilitou ressignificações para a relação escola-universidade.

Nos anos 70, pressupostos da Tecnologia Educacional direcionavam os sistemas de ensino. O futuro professor, ao desenvolver Prática de Ensino, à época identificada como Estágio Supervisionado, deveria vivenciar o tempo de treinamento de habilidades instrumentais consideradas necessárias para a docência. A relação escola-universidade era contexto desse treinamento, no qual não se consideravam demandas, nem identidades das escolas, muito menos os saberes por elas produzidos.

Entende-se que as consequências da Lei. 5692/71, tais como a profissionalização compulsória de professores nas habilitações do $2^{\circ}$ grau e a formação em licenciaturas curtas, igualmente levaram à não separação entre Estágio Curricular Supervisionado e Prática de Ensino. No modelo das licenciaturas " $3+1$ ", que entendia a primazia da teoria em relação à prática, somente o Estágio Supervisionado era responsável pela formação pedagógica do professor.

É possível inferir que, a partir desta referência de primazia da teoria em relação à prática, a relação escola-universidade estava muito aquém de uma efetiva parceria 
OLIVEIRA, R. G de.

(CLARK, 1988) porque não se consideravam condições e necessidades escolares, bem como os objetivos de renovações simultâneas (GOODLAD, 1999).

\begin{abstract}
Parcerias de sucesso não serão criadas por pessoas da universidade preocupadas com a necessidade de promoção pessoal. Nem [...] por pessoas da escola preocupadas com sua sobrevivência na burocracia do sistema escolar. Elas se desenvolverão e florescerão [...] se criadas e sustentadas por educadores que estão dispostos e são capazes de encontrar recompensas pessoais na satisfação dos auto-interesses dos outros [...] serão de valor apenas quando todas as partes procurarem usá-la para a reforma e renovação simultâneas tanto das escolas como das universidades. (CLARK 1988, p. 62).
\end{abstract}

Concepções da Prática de Ensino e do Estágio Curricular Supervisionado nas décadas de 70 e de 80, apontadas por Piconez (1991), Almeida (1994) e Pimenta (2002), foram reelaboradas diante da conscientização da disparidade entre a formação inicial de professores e contextos escolares vivenciados no desenvolvimento do Estágio, contribuindo para isso a superação da sequência observação-participação-regência.

Todavia, se a Lei do Estágio (Lei n 6494/77) vislumbrava para Estágios Supervisionados um caráter socialmente participativo, mesmo considerado como inovador, o Decreto no 87.497/82 não cogitava dimensões formativas que atentassem tanto para a colaboração dos professores das escolas como para os contextos escolares e suas demandas.

A Prática de Ensino e o Estágio Supervisionado foram discutidos no Encontro Nacional de Prática de Ensino, na Faculdade de Educação da USP em 1983. Na preocupação de elaborar um estatuto para o Estágio Supervisionado que o diferenciasse da Prática de Ensino, apresentaram-se dificuldades e conquistas sobre a relação escolauniversidade que subentendiam a necessidade de superação da sequência observaçãoparticipação-regência para o desenvolvimento dos Estágios (OLIVEIRA, 2011).

Igualmente, no final da década de 90, a aprovação da LDBEN de 1996 (Lei no 9.394/96) possibilitou, em parte, inovações na Prática de Ensino e no Estágio Supervisionado que proporcionaram reflexões e consequentes ressignificações para a relação escola-universidade. Primeiro, porque, diferentemente de outros componentes curriculares, o artigo 65 da LDBEN institui para a formação docente, excetuando-se a de ensino superior, a inclusão da Prática de Ensino de no mínimo 300 horas.

Segundo, porque a Lei no 9.394/96 referenciou os pareceres 09/2001 e 28/2001, além das resoluções 01/2002 e 02/2002, todos do Conselho Nacional de Educação/Conselho Pleno (CNE/CP), que instituíram um marco legal para a separação entre Prática de Ensino e Estágio Supervisionado, com diretrizes e cargas horárias diferentes. Atualmente, essas diretrizes e cargas horárias se encontram no Parecer CNE/CP 02/2015 e na Resolução CNE/CP 02/2015, que tomam por fundamentos justificativas e objetivos encontrados nos Pareceres CNE/CP n 09/2001 e n 28/2001 e nas Resoluções nº 01/2002 e no 02/2002.

No Parecer CNE/CP 28/2001 elucidam-se demandas escolares que motivaram as dimensões reflexivas $e$ investigativas na formação inicial de professores, que possibilitariam, para o Estágio Supervisionado, a superação do modelo de observação- 
participação-regência e com potencialidades de instituírem uma parceria escolauniversidade no sentido de Clark (1988) e Goodlad (1999).

\section{BUSCANDO RESSIGNIFICAR A RELAÇÃO ESCOLA-UNIVERSIDADE: ALGUNS RESULTADOS}

A docência como profissão (NÓVOA, 1997; SACRISTAN, 1991; SANTAELLA, 1998; ARROYO, 2000; TARDIF, 2002) e os conceitos de professor reflexivo (SCHÖN, 2000) e professor investigador (ZEICHNER, 2002) têm possibilitado refletir e reelaborar a relação escola-universidade. Considerar a escola como lugar que emana formações e que recebe implicações sociais e culturais contribui para essa reelaboração à medida que evidencia descompassos entre a formação de professores, referendada pela racionalidade técnica e realidades escolares. Na racionalidade técnica, uma atividade profissional prática é fundamentada por uma aplicação rigorosa de uma teoria científica ou uma técnica elaborada externamente ao local da prática (SCHÖN, 2000).

Especificamente para o desenvolvimento do Estágio Supervisionado, a ressignificação da relação escola-universidade tem origem em projetos que integram diferentes disciplinas das licenciaturas e em condições e demandas das escolas (FELDENS, 1983; RUGGIERO, 1983).

Assim, busca-se superar concepções para o desenvolvimento de saberes docentes, nas quais se assume a primazia da universidade em relação à escola, que reflete entendimentos distorcidos para o Estágio Supervisionado, que se estendem à relação professor experiente e futuro professor, configurando uma ineficiente relação entre escola e universidade quando se consideram suas necessidades e demandas.

Desenvolver horas de Estágio Supervisionado a partir de necessidades e condições das escolas e dos cursos de formação de professores, portanto formando uma parceria de valor (CLARK, 1988), tem sido objeto de pesquisas cujos resultados levam a reflexões e reelaborações para a relação escola-universidade.

Oliveira (2011) investigou possibilidades formativas para o futuro professor de Matemática a partir de uma referência de Estágio Supervisionado alternativa ao modelo de observação-participação-regência. Entre os apoios dessa proposta estava a colaboração entre escola e universidade baseada em Clark (1988) e Goodlad (1999). Igualmente, a perspectiva da Cognição Situada (LAVE; WENGER, 1991) referenciou a pesquisa, dada a compreensão da formação docente como um processo relativo a atividades, contexto e cultura na qual se desenvolve.

Participaram da pesquisa 17 estagiários da Licenciatura em Matemática de uma universidade pública paulista, uma professora universitária responsável pela Prática de Ensino e a equipe pedagógica (diretora, coordenadora pedagógica e 4 professoras de Matemática) de uma escola pública de nível fundamental e médio e a pesquisadora.

Os resultados evidenciaram conquistas formativas para os estagiários relativas à identificação com a profissão docente, por aproximação da prática pedagógica, ao confrontarem crenças e experiências prévias, nessa prática, ante supervisão dos professores do Estágio na escola, em uma relação de partilhas, concessões e mudanças de perspectivas. 
OLIVEIRA, R. G de.

A ideia de benefícios mútuos vinculada a uma parceria escola-universidade pode ser entendida a partir de percepções da equipe pedagógica da escola parceira (professores supervisores do Estágio, coordenadora pedagógica e diretora). Com relação aos professores supervisores do Estágio, entre esses benefícios estava a tomada de consciência sobre a corresponsabilidade na formação inicial de professores, que se efetivou de modo positivo diante de reelaborados entendimentos da função do Estágio Supervisionado. Para a diretora e coordenadora, os benefícios se relacionaram com a participação dos futuros professores em atividade extraclasse, podendo expandir a concepção de comunidade escolar e dos saberes nela produzidos.

Esses entendimentos foram certamente motivados na relação mestre-aprendiz não sustentada "[...] pela hierarquia do primeiro em relação ao segundo, mas pela troca de saberes, pela vontade mútua de aprender, não pela junção do velho ao novo, mas pela união de gerações diferentes, com saberes diferentes e, nem por isso, menos importantes" (OLIVEIRA, 2011, p. 235).

Contudo, a relação escola-universidade foi marcada por dificuldades, tais como: resistência de professores e estagiários quanto à ausência de prescrições externas para as horas estagiadas; relutância dos professores das escolas para proporem atividades a serem desenvolvidas conjuntamente com os futuros professores; dificuldade quanto a horários comuns de trabalho colaborativo; identificação de atividades de Estágio com atividades de reforço e de ensino individualizado.

Essa relação motivou ainda outras questões dada "a ausência da institucionalização entre universidade e escola para a efetivação da dimensão prática da formação de professores [...]" (OLIVEIRA, 2011, p. 243) e "[...] as reformas do tipo top down, que não ecoam as vozes de seus principais vetores, os professores das escolas da Educação Básica" (OLIVEIRA, 2011, p. 242). Essas questões se referem à efetiva participação da escola na formação inicial de professores diante da inexistência de condições estruturais e funcionais para isso. Referem-se à origem do tempo comum, por exemplo, na parceria escola-universidade que superasse a boa vontade dos seus participantes.

Ao defender que saberes e tempos de experiência docente dos professores da Educação Básica constituem significativas referências para a formação inicial de professores, Oliveira (2011) questionou a inexistência de uma carga horária própria desses professores para o trabalho colaborativo, subentendido na parceria escola-universidade. Foram realizadas outras questões referentes à participação responsável dos professores das escolas na formação inicial de professores, como um meio de formação continuada, desenvolvendo atitudes que se identificam, mas também podem ir além daquelas relativas ao professor reflexivo e professor pesquisador de sua prática.

Iza e Souza Neto (2015) pesquisaram a parceria escola-universidade no desenvolvimento de Estágios de Educação Física, a fim de identificar elementos para ações mais objetivas entre os participantes e instituições envolvidas nos Estágios. Para essa parceria, foram encontrados quatro desafios. $O$ primeiro desafio se refere à relação vertical com a escola, pois a parceria é vista como chave para a abertura da escola. O segundo desafio passa pelo encontro de "[...] vestígios de uma formação artesanal, em que a maioria dos estagiários [...] fica realmente só na observação [...], observando os mais experientes [...] e aprendendo pela tentativa-erro [...]" (2015, p. 119).

A não institucionalização da relação escola-universidade é o terceiro desafio, implicando o professor em situações fundamentadas em amizades “[...] uma vez que ele 
não foi (in)formado sobre o seu papel no contexto do estágio supervisionado [...]" (2015, p.119). Por fim, o quarto desafio reafirma os apontamentos de Sarti (2009, apud IZA e SOUZA NETO, 2015, p. 120) em decorrência da ausência "[...] de um trabalho articulado entre as instituições responsáveis pela formação dos professores e as escolas que recebem os estagiários".

Iza e Souza Neto, citando como projetos de Estágio e de Extensão e programas que permitem a articulação entre escola e universidade para o Estágio Supervisionado podem superar esses desafios, concluem que "a parceria entre universidade e escola é crucial para o desenvolvimento dos estágios supervisionados na formação de professores, pois ela indica ou não a relação de reciprocidade que pode haver entre duas instituições formadoras e produtoras de conhecimentos". (Idem, 2015, p. 121)

Rodrigues, Cerdas e Paschoalino (2017) pesquisaram a contribuição de saberes de professores da Educação Básica para a relação escola-universidade em trabalhos apresentados em reuniões da Associação Nacional de Pós-Graduação e Pesquisa em Educação (ANPED). No contexto de desenvolvimento do Estágio foram analisados 7 trabalhos porque "[...] enfatizam a centralidade dos professores em seu processo de formação contínua relatando algum tipo de aproximação entre universidade e escola[...]" (2017, p. 3). Assim, esses trabalhos atendiam à ideia de uma efetiva parceria, ao estabelecerem uma colaboração entre professores universitários e os da Educação Básica, pesquisadores e futuros professores.

Na pesquisa, a relação universidade e escola foi caracterizada como colaboração, parceria, rede de formação, encontro ou pesquisa formação/pesquisa colaboração. Sobre o desenvolvimento do Estágio Supervisionado, Rodrigues, Cerdas e Paschoalino (2017) citam as pesquisas de Rodrigues (2012) e Garcia (2015). Rodrigues (2012, apud RODRIGUES, CERDAS e PASCHOALINO, 2017) pesquisou uma parceria construída por professores da escola e da universidade, pesquisadores e estagiários, a fim de pensar em uma proposta formativa para o Estágio Supervisionado. Além da contribuição da experiência na formação de todos os participantes, os resultados apontaram "[...] o desenvolvimento de um novo olhar para a escola e para o aluno, o movimento de uma prática solitária para uma prática solidária, a possibilidade de reflexão sobre a prática [...]" (2017, p. 7).

Garcia (2015, apud RODRIGUES, CERDAS e PASCHOALINO, 2017, p. 9) categorizou a relação escola-universidade como encontro que constitui "[...] fluxos e percursos da formação docente [...]" e como "espaços para a produção de outros-novos saberes, pautados no reconhecimento dos saberes presentes nas práticas docentes e na produção do conhecimento em rede" (idem, 2017, p. 9). Os resultados mostraram que a referência de encontro e os trabalhos com narrativas elaboradas por professores das escolas e futuros professores auxiliaram na perspectiva de processos formativos a partir de diálogos tidos como mais potentes entre a universidade e a escola, que se estendem à própria escola e a seus professores.

UMA POSSIVEL RESSIGNIFICAÇÃO PARA A RELAÇÃO ESCOLA-UNIVERSIDADE A PARTIR DA PARTICIPAÇÃO NA ESCOLA COMO MEIO DE APRENDIZAGEM 
Entendimentos da função do Estágio Supervisionado, tais como unidade entre teoria e prática (PIMENTA, 1994; FREITAS, 1996; MONTEIRO, 2000), reflexão sobre a prática (SCHÖN, 1983, 2000; ZEICHNER, 2002) e aproximação da realidade escolar (PICONEZ, 1991; ALMEIDA, 1994), apresentam dificuldades e conquistas para a relação escolauniversidade. Contudo, igualmente oportunizam uma parceria entre escola e universidade ao considerarem que diferentes objetivos e realidades dessas instituições, no desenvolvimento do Estágio Supervisionado, convergem para aqueles relativos a processos formativos e para renovações de ambas as instituições.

Nesse sentido, o desenvolvimento de horas de Estágio Supervisionado por participação na escola também pode ser considerado contribuinte para a aprendizagem de saberes docentes a partir de condições e demandas escolares. Mas como se pode aprender os saberes específicos de uma profissão? Sobre a origem da aprendizagem, Sfard (1998) defende a dependência entre aprendizagem e contexto, contrariamente à aprendizagem por aquisição.

Desde o início da civilização, a aprendizagem humana é concebida como uma aquisição de algo. [...] Desde a época de Piaget e Vygotski, o desenvolvimento do conhecimento no processo de aprendizagem foi analisado em termos de desenvolvimento conceitual. [...] A linguagem da "aquisição do conhecimento" e do "desenvolvimento conceitual" faz-nos pensar sobre a mente humana como um container a ser enchido com certos materiais e sobre o aprendiz enquanto tornando-se um proprietário destes materiais. (SFARD, 1998, p. 5).

Aprender por participação no Estágio Supervisionado e reconhecer a escola como produtora de saber (TARDIF, 2002; NÓVOA, 1997; PIMENTA, 2002, SACRISTÁN, 1991; PÉREZ-GÓMEZ, 2000) têm levado a reelaborações da relação escola-universidade, em que seus participantes vivenciam experiências diferentes daquelas nas quais ao estagiário cabiam, por exemplo, tarefas como apontar lápis, reproduzir cópias de provas no mimeógrafo, acompanhar alunos ao banheiro e aos professores da escola "[...] deu-se o papel de executar pesquisas em suas salas de aula que foram elaboradas por pesquisadores da Universidade." (ANDERSON; HERR; NIHLEN, 1994 apud PEREIRA, 2002, p. 14).

Conceber o professor da Educação Básica, como um também produtor de conhecimento, estabelece outros princípios para a inserção e participação do futuro professor na escola, que não mais se justificam apenas por um trabalho de observação e crítica, feitas por este, com critérios de validade somente sob aspectos universitários, e isto quando existem critérios que possam assim serem designados. (OLIVEIRA, 2011, p. 100).

Aprender por participação em um contexto vai ao encontro de pressupostos da Cognição Situada (LAVE; WENGER, 1991; BROWN et al., 1989), para a qual a aprendizagem é um processo de enculturação em uma comunidade de práticas que ressignifica a relação mestre-aprendiz por Participação Periférica Legítima (LAVE; WENGER, 1991). A Participação Periférica Legítima é um processo no qual o aprendiz desenvolve habilidades 
associadas às práticas da cultura da qual está participando, primeiramente com atividades periféricas, que gradualmente se aproximam das atividades culturais centrais (LAVE; WENGER, 1991).

No Brasil, princípios da Cognição Situada podem ser encontrados em fundamentos para as licenciaturas (PARECER CNE/CP 09/2001; RESOLUÇÃO CNE/CP 02/2002), que se estendem às atuais diretrizes para a formação de professores da Educação Básica (PARECER CNE/CP 02/2015; RESOLUÇÃO CNE/CP 02/2015).

Ao apresentarem afinidades de compreensão pedagógica entre princípios da Cognição Situada e diretrizes curriculares nacionais para a formação de professores, Oliveira e Di Giorgi (2011) afirmam que questões sobre essa formação se apresentam e são enfrentadas nos campos institucional e curricular, citando que, no Parecer CNE/CP 09/2001, essas questões transitam entre "a desconsideração do repertório de conhecimento dos professores em formação" e vão até "a desconsideração das especificidades próprias da educação básica e das áreas que compõem o quadro curricular na educação básica" (OLIVEIRA; DI GIORGI, 2011, p. 362).

Uma das questões que permitem ressignificar a relação escola-universidade remete às ideias equivocadas sobre a Prática de Ensino, com consequentes polarizações entre disciplinas pedagógicas e específicas e atividades formativas baseadas em "[...] uma concepção aplicacionista das teorias, não se comunicando com a agenda e realidades das escolas [...]" (OLIVEIRA; DI GIORGI, 2011, p. 362) e às "[...] atividades realizadas no estágio supervisionado, que desprezam o aspecto teórico dos conteúdos, desembocando em uma concepção ativista de prática [...]" (OLIVEIRA; DI GIORGI, 2011, p. 362).

Princípios da Cognição Situada e do conceito de Participação Periférica foram aportes teóricos da pesquisa de Oliveira (2011) que, através de parceria escolauniversidade, propôs horas de Estágio que superassem o modelo de observaçãoparticipação-regência.

Nas horas de Estágio Supervisionado, a relação professor experiente e futuro professor não foi marcada pela função de transmissão e de recepção de saberes acumulados. Ao contrário, foi uma relação mútua de ensino e aprendizagem construída a partir de ações e reflexões sobre atividades, situações e participações no contexto escolar. Estar com professor experiente em situações didático-pedagógicas, que propiciaram o desenvolvimento de saberes docentes, levou à superação de críticas sobre a escola, muitas vezes isentas de ações e de fundamentadas reflexões.

Para Oliveira (2011), a relação escola-universidade, no contexto da pesquisa, foi uma efetiva parceria escola-universidade (CLARK, 1998; GOODLAD, 1999), pois o Estágio Supervisionado foi desenvolvido por aproximação à regência (Participação Periférica), que oportunizou desenvolver necessários saberes docentes, a partir de processos adaptativos, mas também de processos criativos, dada a utilização de ferramentas conceituais associadas ao contexto escolar.

Assim, inserir-se na escola é comprometer-se com o sistema de valores e de elementos daquela comunidade escolar, o que não significa que as ações se apresentam unicamente como adaptativas já que, para Lave e Wenger (1991), a transformação ocorre tanto para o indivíduo, como para a comunidade. (OLIVEIRA, 2011, p. 102). 


\section{PARCERIAS ESCOLA-UNIVERSIDADE: POSSIBILIDADES INSTITUCIONALIZADAS PELOS PROGRAMAS PIBID E RESIDÊNCIA PEDAGÓGICA}

A despeito de dificuldades de diferentes naturezas (interesses pessoais, agendas institucionais, tempo, distância...), a parceria escola-universidade no desenvolvimento da Prática de Ensino e do Estágio Supervisionado mostrou ser um caminho para a conquista de mútuos benefícios e de renovações simultâneas (CLARK, 1988, GOODLAD, 1999), necessariamente aqueles relativos à elaboração de saberes, da formação inicial e da formação continuada de professores, a partir de problematizações e ações no contexto escolar (OLIVEIRA, 2011; IZA; SOUZA NETO, 2015; RODRIGUES; CERDAS; PASCHOALINO, 2017; RODRIGUES, 2012 e GARCIA 2015 apud RODRIGUES; CERDAS; PASCHOALINO, 2017).

No entanto, tornou-se um dos maiores desafios para o desenvolvimento da Prática de Ensino e do Estágio Supervisionado firmar uma parceria escola-universidade que não dependesse de interesses pessoais e, em muitos casos, da boa vontade de professores das escolas e das licenciaturas e que fosse um espaço de positiva qualidade de formação compartilhada (inicial e contínua) de professores, o que levaria a ressignificar o papel da escola e o papel da universidade nessa formação.

Programas de melhoria para a qualidade dessa formação, cujos objetivos subentendem a ressignificação da relação escola-universidade, foram implementados no Brasil a partir de políticas públicas educacionais e da Política Nacional de Formação de Professores. Como exemplo, o Programa de Bolsa Institucional de Iniciação à Docência (PIBID) (lançado por edital em 2007 e implementado em 2009) e o Programa de Residência Pedagógica (lançado por edital e implementado em 2018), ambos numa parceria entre a Secretaria de Educação Superior do Ministério da Educação (SESu/MEC), a Coordenação de Aperfeiçoamento de Pessoal de Nível Superior (CAPES) e o Fundo Nacional de Desenvolvimento da Educação (FNDE).

Objetivos do PIBID remetem à relação escola-universidade quando propõem a inserção de licenciandos nas escolas com o objetivo de criar e de participar de atividades que busquem entender e superar problemas didático-pedagógicos por apropriação e reflexão de instrumentos, saberes e características do trabalho docente. Às escolas cabe o incentivo para que seus professores entendam e assumam o papel de coformadores e protagonistas da formação de professores (BRASIL, 2010).

Nos documentos não aparece detalhadamente como a função dos supervisores deve ser desempenhada, o que representa uma conquista para estes professores, [...] fica garantida sua autonomia dentro da sala de aula, amplamente defendida pelos agentes do campo educacional, visto que o caminho para a humanização do espaço escolar passa pela liberdade de escolha e pela responsabilidade na tomada de decisões. (SIMÃO, DIAS E BARBOSA 2018, p. 43).

No PIBID, professores que participam dos projetos nas escolas (Professores Supervisores), licenciandos e professores universitários (Coordenadores Institucionais e Coordenadores de Área) são bolsistas (APES. Implicações do PIBID quanto à ressignificação da relação escola-universidade, considerando questões de superação do 
distanciamento entre as duas instituições, que levem à construção de um comum espaço formativo docente, têm sido apresentadas em pesquisas e relatos de experiências.

Para avaliar o papel indutor do PIBID, em 2014 pesquisadores da Fundação Carlos Chagas desenvolveram um estudo aplicando um questionário on-line cuja análise das respostas de Professores Supervisores, Coordenadores de Área, Coordenadores Institucionais e Licenciandos Bolsistas fundamentou-se em questões da formação inicial de professores e na "[...] necessidade de aproximar o campo de formação e de atuação profissional" (FUNDAÇÃO CARLOS CHAGAS, 2014, p. 13). Questões abertas abordavam contribuições do PIBID para a escola e para a formação profissional dos participantes.

Nas contribuições do PIBID para a relação escola-universidade houve convergência de respostas dos Professores Supervisores, Coordenadores de Área e Coordenadores Institucionais, que permitem entender o alcance de objetivos do PIBID quanto à diminuiç̧ão da distância entre essas instituições e igualmente no entendimento de responsabilidade mútua para a formação de professores ao oportunizar colaboração profissional entre as duas instituições.

O PIBID possibilitou a superação da Prática de Ensino nas escolas como espaço/tempo de aplicação de conhecimentos e teorias externamente a elas desenvolvidos. Nas respostas dos participantes foi comum o apontamento de discussões, diálogos e partilhas sugerindo a participação no Programa, sem hierarquias de saberes entre instituições, mas com saberes próprios que se expandem ao se complementarem, revelando a valorização da escola pública e de seus professores, valorização considerada fundamental para uma efetiva parceria escola-universidade.

Do mesmo modo que o PIBID, o Programa de Residência Pedagógica (EDITAL CAPES, No 06/2018) apresenta justificativas e objetivos específicos que se mostram promissores para essa efetiva parceria, apesar de críticas, de questionamentos e de rejeição, como apresentado na Manifestação das Entidades Educacionais Sobre a Política de Formação de Professores Anunciada pelo MEC (ANPED, 2017).

Silva e Cruz (2018, p. 239) criticam o Programa de Residência Pedagógica argumentando que em seus objetivos as atividades e reflexões relativas ao trabalho docente são induzidas verticalmente porque vinculam “[...] as ações de estágio relacionadas as aprendizagens dispostas na BNCC [...]" e enfatizam "[...] atividades práticas, entendidas como imersão na sala de aula centrando o ato pedagógico no fazer metodológico-curricular". Igualmente, criticam a vinculação entre o Estágio Supervisionado e a imersão na prática, pois revela a fragmentação da unidade teoria e prática, imprimindo uma concepção utilitarista para a formação docente. Assim, é necessário propor "[...] elementos e princípios para pensar uma residência pedagógica [...] em um caráter crítico-emancipador" (SILVA; CRUZ, 2018, p. 242).

A opção pelo pragmatismo utilitarista [...] na formação de professores, implica [...] a escolha de uma concepção de educação que vê as relações de produção capitalista como principal fonte referenciadora. [...] uma concepção de Residência docente por ser apontada como 'aprimoramento' do estágio supervisionando, está sendo vinculada ao aprender a aprender centrada numa prática esvaziada de teoria e política. (SILVA; CRUZ, 2018, p. 238). 
A despeito de críticas, questionamentos e rejeições, a participação no Programa de Residência Pedagógica possibilita resultados positivos que referenciem a formação inicial e continuada de professores, além da ressignificação da relação escolauniversidade. Essa possibilidade ocorre a partir de seus objetivos (EDITAL CAPES, No 06/2018), entre eles o de aperfeiçoar a formação de futuros professores, que desenvolverão projetos que "[...] fortaleçam o campo da prática [...]", possibilitando "[...] exercitar [...] a relação entre teoria e prática profissional docente, utilizando coleta de dados e diagnóstico sobre o ensino e a aprendizagem escolar, entre outras didáticas e metodologias".

Essa possibilidade também se encontra na exigência (EDITAL CAPES, № 06/2018) para que os subprojetos institucionais descrevam a "[...] realidade educacional na qual as escolas-campo do subprojeto estão inseridas, incluindo as expectativas e sugestões dos dirigentes das redes de ensino ao qual pertencem essas escolas"; bem como na descrição da "percepção de como esses gestores podem contribuir para o desenvolvimento da residência pedagógica, enquanto estratégia para aperfeiçoar a prática na formação inicial dos professores da educação básica".

Para o Programa de Residência Pedagógica, dado seu tempo de existência, ainda não há resultados de percursos e práticas pedagógicas disponibilizados em pesquisas ou relatos de experiências sobre suas consequências para a relação escola -universidade.

No entanto, sua origem como resultado de políticas de melhoria para a formação de professores e seus objetivos, que focalizam de forma direta e indireta a relação escolauniversidade, quando associados às orientações para a caracterização dos projetos institucionais, podem ser considerados, assim como são os do PIBID, facilitadores para que a relação escola-universidade seja referenciada por uma parceria, que fundamente o alcance de renovações e benefícios para as duas instituições, necessariamente aqueles demandados pela formação inicial e continuada de professores.

\section{CONSIDERAÇÕES FINAIS}

Na relação escola-universidade, desde que contextualizado o desenvolvimento da Prática de Ensino e do Estágio Supervisionado, encontram-se dificuldades, desafios e conquistas. Da escola como espaço de fruição de diversas concepções da formação docente na universidade, que em sua maioria fundamentaram atividades formativas de futuros professores, ignorando realidades e demandas escolares, para a escola reconhecida como produtora de saberes docentes e como coformadora de futuros professores, temos igualmente dificuldades, desafios e conquistas.

Todavia, dificuldades, desafios e conquistas em um contexto de implementação de programas nacionais para a melhoria da formação de professores, tais como o PIBID e o Residência Pedagógica, motivam a ressignificação da relação escola-universidade. Isso ocorre a partir de reflexões e ações diante de suas justificativas e objetivos, que levam a entender a colaboração entre professores das escolas e das universidades como pilar de corresponsabilidade para a formação de capacidades profissionais de professores e de futuros professores em consonância com nossa realidade educacional. 
RESSIGNIFICATING THE SCHOOL-UNIVERSITY RELATIONSHIP BY THE TIME: DIFFICULTIES, CHALLENGES AND CONQUESTS

ABSTRACT: The Resolution No. 09/69 of the Federal Council of Education established the compulsory Teaching Practice in the teacher education in the form of Student Teaching. Motivated by the commemoration of the 50th anniversary of its publication, we present a brief historical incursion of Teaching Practice and Student Teaching for teacher education, taking into account the school - university relationship as a contex, and as the challenges and achievements of this relationship have contributed to its resignification in terms of a partnership, considering the relational and formative demands of schools and of teacher education.

KEYWORDS: Partnership. Teaching. Teaching Practice. Student Teaching.

RESIGNIFICANDO LA RELACIÓN ESCUELA - UNIVERSIDAD POR EL TIEMPO: DIFICULTADES, DESAFÍOS Y CONQUISTAS

RESUMEN: La Resolución № 09/69 del Consejo Federal de Educación estableció como obligatoria la práctica docente en los cursos de pregrado, en forma de la Pasantía Supervisada. Motivados por la conmemoración del 50 aniversario de su publicación, presentamos una breve incursión histórica, sobre la realización de la Práctica de Enseñanza y de la Etapa Supervisada de formación de profesores, teniendo como contexto la relación escuela - universidad, y como desafíos y conquistas de esa relación, que se presentan por el tiempo han contribuido a su resignificación, en términos de una colaboración, al considerar demandas relacionales y formativas, tanto las de las escuelas y las de la formación de profesores.

PALABRAS CLAVE: Colaboración. Enseñanza. Práctica de Enseñanza. Pasantía Supervisada.

\section{REFERÊNCIAS}

ALMEIDA, J. S. Estágio supervisionado em prática de ensino - relevância para a formação ou mera atividade curricular? Revista ANDE, v.13, n. 20, p. 39-42, 1994.

ARROYO, M. Ofício de Mestre: Imagens e Auto-Imagens. Petrópolis: Vozes, 2000.

BRASIL. CAPES. Edital no 06/2018. Programa de Residência Pedagógica. Disponível em: http://capes.gov.br/images/stories/download/editais/01032018-Edital-6-2018Residencia-pedagogica.pdf. Acesso em: 13 jan. 2019.

BRASIL. CAPES. Lei no 4.024 de 20 de dezembro de 1961. Fixa as Diretrizes e Bases para a Educação Nacional. Disponível em: 
https://presrepublica.jusbrasil.com.br/legislacao/108164/lei-de-diretrizes-e-base-de1961-lei-4024-61. Acesso em: 13 jan. 2019.

BRASIL. CAPES. Conselho Federal de Educação. Parecer n. ${ }^{\circ} 292$, de 14 de novembro de 1962. CONSELHO FEDERAL DE EDUCAÇÃO. Currículos mínimos dos cursos de graduação. Brasília: Departamento de Documentação e Divulgação, 1979, p. 45-48.

BRASIL. CAPES. Ministério da Educação e Cultura. Conselho Federal de Educação. Documenta, no 105, p. 117-118, 1969.

BRASIL. CAPES. Lei no 5.692 de 11 de Agosto de 1971. Fixa Diretrizes e Bases para o ensino de $1^{\circ}$ e $2^{\circ}$ graus. Disponível em: http://www2.camara.leg.br/legin/fed/lei/19701979/lei-5692-11-agosto-1971-357752-publicacaooriginal-1-pl.html. Acesso em: 13 jan. 2019.

BRASIL. CAPES. Lei no 6.494 de 7 de Dezembro de 1977. Dispõe sobre os estágios de estudantes de estabelecimento de ensino superior e ensino profissionalizante do $2^{\circ}$ Grau e Supletivo e dá outras providências. Diário Oficial da União, Brasília, 1977.

BRASIL. CAPES. Lei de Diretrizes e Bases da Educação Nacional. Lei no 9394 de 20 de Dezembro de 1996. Diário Oficial da União, Brasília, 1996.

BRASIL. CAPES. MEC. CNE/CP. Parecer no 09 de 08 de Maio de 2001. Disponível em: http://portal.mec.gov.br/cne/arquivos/pdf/009.pdf . Acesso em: 13 jan. 2019.

BRASIL. CAPES. MEC. CNE/CP. Parecer no 28 de 02 de Outubro de 2001. Disponível em: http://portal.mec.gov.br/cne/arquivos/pdf/028.pdf. Acesso em: 13 jan. 2019.

BRASIL. CAPES. MEC. CNE/CP. Parecer no 02 de 09 de Junho de 2015. Disponível em: http://portal.mec.gov.br/observatorio-da-educacao/30000-uncategorised/21123-2015pareceres-do-conselho-pleno Acesso em: 13 jan. 2019.

BRASIL. CAPES. MEC. CNE/CP. Resolução no 01 de 18 de Fevereiro de 2002. Disponível em: http://portal.mec.gov.br/seesp/arquivos/pdf/res1_2.pdf . Acesso em 13 jan. 2019.

BRASIL. CAPES. MEC. CNE/CP. Resolução no 02 de 19 de Fevereiro de 2002. Disponível em: http://portal.mec.gov.br/cne/arquivos/pdf/CP022002.pdf. Acesso em: 13 jan. 2019.

BRASIL. CAPES. MEC. CNE/CP. Resolução no 02 de 01 de Julho de 2015. Disponível em: http://portal.mec.gov.br/docman/agosto-2017-pdf/70431-res-cne-cp-002-03072015pdf/file Acesso em: 13 de jan de 2019.

BROWN, J. S.; COLLINS, A.; DUGUID, P. Situated Cognition and the Culture of Learning. Educational Researcher, n. 18, p. 32-42, 1989. 
CLARK, Richard. School-University Relationships: An Interpretative Review. In: SIROTNIK, K.; GOODLAD, J. (Eds). School-University Partnerships in Action. Concepts, Cases and Concerns. New York: Teachers College Press, 1988.

FELDENS, M. G. F. Pesquisa em Educação de Professores: antes, agora e depois? In: Fórum Educacional. Rio de Janeiro, v. 7, p. 26-44, 1983.

FUNDAÇÃO CARLOS CHAGAS. Um Estudo Avaliativo do Programa Institucional de Iniciação à Docência (Pibid). São Paulo: Fundação Carlos Chagas, 2014. Disponível em: http://www.capes.gov.br/images/stories/download/bolsas/24112014-pibidarquivoAnexado.pdf. Acesso em: 13 jan. 2019.

GOODLAD, J. Simultaneously renewing schools and teacher education: Perils and promises. In: R. Clark (Ed.). Effective professional development schools. San Francisco: Jossey-Bass, 1999.

IZA, D. F. V; SOUZA NETO, S. Os desafios do estágio curricular Supervisionado em educação física na Parceria entre universidade e escola. Movimento, Porto Alegre, v. 21, n. 1, p. 111-124, 2015.

LAVE, J.; WENGER, E. Situated Learning. Legitimate Peripheral Participation. Cambridge University Press, 1991.

NÓVOA, A. Formação de Professores e Profissão Docente. In: NÓVOA. A. (Org). Os Professores e a sua Formação. Lisboa: Publicações Dom Quixote. Instituto de Inovação Educacional, 1997.

OLIVEIRA, R. G. Estágio Supervisionado: Horas de Parceria Escola - Universidade. Jundiaí: Paco Editorial, 2011.

OLIVEIRA, R. G.; DI GIORGI, C. Princípios da cognição situada e as diretrizes curriculares nacionais para a formação de professores. Educação, Porto Alegre, v. 34, n. 3, p. 360-368, 2011.

PEREIRA, J. A Pesquisa dos Educadores como Estratégia para Construção de Modelos Críticos de Formação Docente. In: PEREIRA, J.; ZEICHNER, K. (Orgs). A Pesquisa na Formação e no Trabalho Docente. Belo Horizonte: Autêntica, 2002.

PÉREZ-GÓMEZ, A. I. Ensino para a Compreensão. In: SACRISTÁN, J. G.; PÉREZ-GÓMEZ, A. I. Compreender e Transformar o Ensino. Porto Alegre: Artmed, 2000. 
OLIVEIRA, R. G de.

PICONEZ, S. B. A Prática de Ensino e o Estágio Supervisionado: A Aproximação da Realidade Escolar e a Prática da Reflexão. In: PICONEZ, S. B. (Org). A Prática de Ensino e o Estágio Supervisionado. Campinas: Papirus, 1991.

PIMENTA, S. G. O Estágio na Formação de Professores: Unidade Teoria e Prática? São Paulo: Cortez, 2002.

RODRIGUES, P. A. M; CERDAS, L.; PASCHOALINO, J. B. Aproximações e propostas de parceria entre universidade e escola na formação de professores: uma análise a partir dos trabalhos apresentados nas últimas cinco edições da ANPEd (2010-2015). In: Anais... São Luis Maranhão: ANPEd, p. 1-16, 2017.

RUGGIERO, M. A Prática de Ensino e o Estágio Supervisionado. In: Atas do Encontro Nacional de Prática de Ensino. Faculdade de Educação da USP, p. 7-83, 1983.

SACRISTAN, J. G. Consciência e Acção Sobre a Prática Como Libertação Profissional dos Professores. In: NÓVOA, A. (Org). Profissão Professor. Lisboa: Livros Horizonte, 1991.

SANTAELLA, C. Formación para la Profesión Docente. Grupo Force y Grupo Editorial Universitario, 1998.

SCHÖN, D. Educando o Profissional Reflexivo: Um Novo Design para o Ensino e a Aprendizagem. Porto Alegre: Artes Médicas Sul, 2000.

SFARD, A. On Two Metaphors for Learning and the Dangers of Choosing Just One. Educational Researcher, v. 27, n² 2, p. 4-13, 1998.

SILVA, K.; CRUZ, S. A Residência Pedagógica na formação de professores: história, hegemonia e resistências. Momento: diálogos em educação, v. 27, n. 2, p. 227-247, 2018.

SIMÃO, F.; DIAS, J.; BARBOSA, R. Considerações sobre o PIBID: subprojeto de Ciências Biológicas da UNESP de Assis. In: MENDONÇA, S. G. et al. (Orgs). PIBID/UNESP. Forma(a)ação de professores: percursos e práticas pedagógicas em ciências exatas e da natureza. São Paulo: Cultura Acadêmica, 2018.

TARDIF, M. Saberes Docentes e Formação Profissional. Petrópolis: Vozes, 2002.

ZEICHNER, K. A Pesquisa-Ação e a Formação Docente Voltada para a Justiça Social: Um Estudo de Caso dos Estados Unidos. In: PEREIRA, J. D.; ZEICHNER, K. (Orgs). A Pesquisa na Formação e no Trabalho Docente. Belo Horizonte: Autêntica, 2002. 
Raquel Gomes de OliverRA: Possui Licenciatura em Matemática pela Universidade Estadual Paulista Júlio de Mesquita Filho (UNESP, 1991), mestrado em Educação pela Universidade Estadual de Campinas (UNICAMP, 1996) e doutorado em Educação pela Universidade de São Paulo (USP, 2006). Atualmente é coordenadora de um projeto CAPES de Residência Pedagósica em Matemática e membro do do Grupo de Pesquisa "Ensino e Aprendizagem como Objeto da Formação de Professores" (GPEA) da FCT/Unesp, cadastrado no Diretório de Grupos de Pesquisa do CNPq e certificado pela UNESP

Orcid: http://orcid.org/0000-0002-0217-2629

E-mail: raquel.g.oliveira@unesp.br

Este periódico utiliza a licença Creative Commons Attribution 3.0, para periódicos de acesso aberto (Open Archives Iniciative - OAI). 